\title{
Survival, Neurologic Injury, and Kidney Function after Surgery for Acute Type A Aortic Dissection
}

\author{
Felix Schoenrath ${ }^{1}$ Raffael Laber ${ }^{2}$ Mergime Maralushaj ${ }^{2}$ Deborah Henzi ${ }^{2}$ Etem Ibrahim Caliskan ${ }^{2}$ \\ Burkhardt Seifert ${ }^{3}$ Dominique Bettex ${ }^{4}$ Christoph Thomas Starck ${ }^{1}$ Martin Czerny ${ }^{5}$ Volkmar Falk ${ }^{1}$
}

${ }^{1}$ Department of Cardiothoracic and Vascular Surgery, Deutsches Herzzentrum Berlin, Berlin, Germany

${ }^{2}$ Clinic for Cardiovascular Surgery, University Hospital Zurich, Zurich, Switzerland

${ }^{3}$ Department of Biostatistics, Epidemiology, Biostatistics and Prevention Institute, University of Zurich, Zurich, Switzerland

${ }^{4}$ Institute of Anesthesiology University Hospital Zurich, Zurich, Switzerland

${ }^{5}$ Department of Cardiothoracic and Vascular Surgery, University of Freiburg, Freiburg, Baden-Würtemberg, Germany
Address for correspondence Felix Schoenrath, MD, Department of Cardiothoracic and Vascular Surgery, Deutsches Herzzentrum Berlin, Augustenburger Platz 1, Berlin, Germany (e-mail: schoenrath@dhzb.de).

Thorac Cardiovasc Surg 2016;64:100-107.

\begin{abstract}
Keywords

- aorta/aortic

- database

- kidney

Background To analyze survival, neurologic injury, and kidney function after acute type $\mathrm{A}$ aortic dissection.

Methods A total of 445 patients undergoing surgery for acute type $A$ aortic dissection were analyzed. Evaluation according to risk factors for mortality, neurologic injury, and kidney function was performed.

Results Overall 1-, 5-, and 10-year survival rates were $82.8 \pm 1.8 \%, 73.6 \pm 2.4 \%$, and $59.3 \pm 3.9$, respectively. Independent preoperative risk factors for mortality were preexisting renal impairment $(p=0.001)$, reduced left ventricular ejection fraction $(p<0.001)$, and age $(p<0.001)$. Perioperative risk factors were prolonged crossclamp $(p<0.001)$ and cerebral perfusion time $(p=0.001)$. Risk factors for renal failure were preexisting renal impairment $(p<0.001)$, prolonged cross-clamp time $(p<0.001)$, cerebral perfusion time $(p<0.001)$, and age $(p=0.022)$. Risk factors for neurologic injury were cross-clamp time $(p=0.038)$, cerebral perfusion time $(p=0.007)$, and age $(p=0.045)$.

Conclusion In addition to classic risk factors, survival after type $A$ aortic dissection is affected by preexisting renal impairment. Preexisting renal impairment is predictive of postoperative renal failure. Therefore treatment and prevention strategies for renal failure during the acute and long-term course after acute type A aortic dissection are warranted.
\end{abstract}

\section{Introduction}

Outcome after surgery for type A aortic dissection has been continuously improving over the last decade. ${ }^{1}$ Major conceptual improvements have been the routine use of the right subclavian artery for arterial inflow, selective antegrade

received

March 28, 2015

accepted after revision

June 23, 2015

published online

September 3, 2015

cerebral perfusion, and a trend toward less extensive core temperatures during hypothermic circulatory arrest. ${ }^{2} \mathrm{Nev}-$ ertheless, there is still room for improvement, in particular about neurologic outcome as well as about any type of preoperative malperfusion syndrome, as this is known to substantially affect the outcome. ${ }^{2,3}$

(c) 2016 Georg Thieme Verlag KG Stuttgart · New York
DOI http://dx.doi.org/ 10.1055/s-0035-1563536. ISSN $0171-6425$. 
Table 1 Follow-up characteristics of the cohort

\begin{tabular}{|l|l|}
\hline Total no. of patients & 445 \\
\hline Sum of follow-up years & 1,707 \\
\hline Follow-up $>3$ mo or deceased & 430 \\
\hline Follow-up $>3$ mo & 308 \\
\hline Information by patient & 235 \\
\hline Information by general practitioner & 32 \\
\hline Data from CCIF & 41 \\
\hline Deceased patients & 122 \\
\hline No follow-up $>3$ mo & 15 \\
\hline
\end{tabular}

Abbreviation: CCIF, computed clinical information system.

This study aims to analyze survival, kidney function, and neurologic injury after surgery for acute type A aortic dissection in a large single-center cohort.

\section{Materials and Methods}

\section{Study Cohort and Follow-up Modality}

We analyzed 445 patients having undergone surgery for acute type $\mathrm{A}$ aortic dissection in our institution between 2001 and 2013. In 2013 all expected alive patients were contacted and written informed consent was obtained. In case of inability to reach an individual, the last documented follow-up available in our records was used. The local ethics committee approved the study (KEK-ZH-Nr. 2012-0039). The contact algorithm is shown in - Table 1. Descriptive characteristics of the patient cohort are given in - Table 2. Median follow-up was 3.0 (range: $0-12.5$ ) years.

\section{Anesthesiologic Management}

Patients did not receive any premedication as for emergency procedure. Anesthesia induction and maintenance were standardized for all cases. A rapid sequence induction with midazolam $(0.05-1 \mathrm{mg} / \mathrm{kg})$, etomidate $(0.2 \mathrm{mg} / \mathrm{kg})$, for hemodynamic unstable patients or propofol bolus $(1-3 \mathrm{mg} / \mathrm{kg}$ ) for hemodynamic stable patients, with fentanyl $(5 \mu \mathrm{g} / \mathrm{kg})$, and rocuronium $(1 \mathrm{mg} / \mathrm{kg})$ was used. Anesthesia was maintained with Sevorane (1.5-3 vol\%) or propofol $(2-3 \mu \mathrm{g} / \mathrm{mL})$, continuous perfusion of remifentanil $(0.1-0.5 \mu \mathrm{g} / \mathrm{kg} / \mathrm{min})$, and additional boli of rocuronium as needed. Anesthetic monitoring included American Society of Anesthesiologists routine monitors, two to three invasive blood pressures of the upper and/or lower extremities (via the left and right radial and femoral arteries), nasopharyngeal, and bladder temperature measurements. A four-lumen central venous catheter (7 F; Arrow, Reading, Pennsylvania, United States) and sheath (8.5 F; Arrow) were placed in the right internal jugular vein. At the end of anesthesia induction, a multiplane transesophageal echocardiography probe was inserted (Philips Medical Systems, Andover, Massachusetts, United States). Intraoperative, cerebral perfusion was monitored with continuous bilateral near-infrared oximetry (NIRS-Invos, Covidien, Mansfield, Massachusetts, United States). The simultaneous performance of a processed electroencephalogram (BIS, Aspect Medical Systems, Norwood, Massachusetts, United States) allowed the confirmation of burst suppression before initiation of hypothermic circulatory arrest. After median sternotomy, heparin ( $500 \mathrm{IU} / \mathrm{kg}$ ) was given to achieve an activated clotting time of more than 350 seconds before cardiopulmonary bypass (CPB) and 500 seconds during bypass, with additional boli of 5000 to 10,000 IU if the activated clotting time did not reach the target values. CPB was primed with 10,000 IU of heparin. Simultaneously with heparin, tranexamic acid (30 mg/kg, maximal dose of $2 \mathrm{~g}$ ) was administered intravenously. Therefore, besides premedication, anesthesiologic management was comparable to standardized management as published elsewhere. ${ }^{4}$

\section{Conduction of Extracorporeal Circulation and Myocardial Protection Strategy}

Patients were cooled to $20^{\circ} \mathrm{C}$ nasopharyngeal temperature and between $26^{\circ} \mathrm{C}$ and $28^{\circ} \mathrm{C}$ bladder temperature. Vasodilators such as phentolamine were used to achieve homogeneous cooling by reducing peripheral vascular resistance. During rewarming, targets were $36^{\circ} \mathrm{C}$ nasopharyngeal temperature and $35^{\circ} \mathrm{C}$ core temperature, comparable to strategies published elsewhere. ${ }^{4}$ Cardioplegia was given as to institutional standards. After termination of ECC, reversal of heparin with a protamine ratio of $1: 1$ ( $1 \mathrm{mg}$ protamine per 100 IU heparin) was performed. An intraoperative autologous transfusion device with reinfusion of shed mediastinal blood and remaining ECC blood was frequently used. Intraoperative and postoperative transfusion regimens and coagulation management were guided by in-hospital standards (institutional algorithm) following rotational thromboelastometry (ROTEM, Pentapharm $\mathrm{GmbH}$, Munich, Germany) and laboratory analysis of selected parameters of coagulation.

\section{Definition of Clinical Parameters}

Preoperative parameters were defined according to EuroSCORE guidelines. ${ }^{5}$ Evaluated outcomes included longterm morbidity and mortality. Morbidity focused on postoperative renal failure with need for dialysis and occurrence of stroke (ischemic and hemorrhagic). Preoperative renal impairment was defined as preoperative creatinine greater than $200 \mu \mathrm{mol} / \mathrm{L}$. No patient of the entire cohort was on renal replacement therapy prior to acute type A aortic dissection. Postoperative dialysis was stratified into need for acute (new onset of dialysis) or chronic renal replacement therapy for longer than 1 year after surgery or until death. The long-term setting had been appointed to exclude influences from concomitant effects of the acute setting, for example, distributive shock, sepsis, and malperfusion. Neurologic injury was defined as any newly developed sensorimotor deficit persisting at any point of follow-up combined with a morphologic correlate in cranial computed tomography. This definition of stroke was formulated to be conservative, considering that not all patients had routine neurologic consults postdissection. No evaluation of spinal cord ischemia was performed. 
102 Survival, Neurologic Injury, and Kidney Function after Aortic Dissection Schoenrath et al.

Table 2 Descriptive characteristics of the cohort $(n=445)^{\mathrm{a}}$

\begin{tabular}{|c|c|}
\hline Demographics & \\
\hline Age, mean, SD, y & $62.7 \pm 13.3$ \\
\hline Age $>70$ y, $n(\%)$ & $148(33)$ \\
\hline Age $>80 \mathrm{y}, n(\%)$ & $35(8)$ \\
\hline Female, $n(\%)$ & $122(27)$ \\
\hline \multicolumn{2}{|l|}{ Chronic health conditions and risk factors } \\
\hline Chronic obstructive pulmonary disease, $n$ (\%) & $47 / 436(11)$ \\
\hline Renal impairment (creatinine $>200 \mu \mathrm{mol} / \mathrm{L}), n(\%)$ & $27 / 439(6)$ \\
\hline Diameter ascending aorta $>45$ mm, $n(\%)$ & $277 / 440(63)$ \\
\hline Arterial hypertension (RR syst > $140 \mathrm{~mm} \mathrm{Hg}$ ), $n(\%)$ & $296 / 379(78)$ \\
\hline Diabetes mellitus, $n(\%)$ & $21 / 242(9)$ \\
\hline BMI, mean, SD & $26.8 \pm 4.6$ \\
\hline \multicolumn{2}{|l|}{ Preoperative assessment } \\
\hline EuroSCORE, additive, mean, SD & $11 \pm 3$ \\
\hline Redo surgery, $n(\%)$ & $22(5)$ \\
\hline Preoperative tamponade, $n$ (\%) & $64 / 440(15)$ \\
\hline Left ventricular dysfunction (LVEF < 55\%), n (\%) & $191 / 420(46)$ \\
\hline Left coronary artery affected by dissection, $n(\%)$ & $31 / 440(7)$ \\
\hline $\begin{array}{l}\text { Right coronary artery affected by dissection, } n(\%) \\
\text { Cardiogenic shock }\end{array}$ & $\begin{array}{l}57 / 440(13) \\
45 / 442(10)\end{array}$ \\
\hline \multicolumn{2}{|l|}{ Intraoperative assessment } \\
\hline Cross-clamp time (min), median, (IQR) & $91(55)$ \\
\hline Total circulatory arrest time (min), median, (quartile 3) & $2(17)$ \\
\hline Selective cerebral perfusion (min), median, (IQR) & $28(20)$ \\
\hline Antegrade cerebral perfusion, $n(\%)$ & $375 / 414(91)$ \\
\hline Retrograde cerebral perfusion, $n(\%)$ & $12 / 406(3)$ \\
\hline \multicolumn{2}{|l|}{ Extent of operation } \\
\hline \multicolumn{2}{|l|}{ Valve } \\
\hline Bentall procedure, $n(\%)$ & $125 / 445(28)$ \\
\hline Resuspension, $n(\%)$ & $138 / 445(31)$ \\
\hline \multicolumn{2}{|l|}{ Arch } \\
\hline Hemiarch replacement, $n(\%)$ & $240 / 445(54)$ \\
\hline Total arch replacement, $n(\%)$ & $50 / 445(11)$ \\
\hline \multicolumn{2}{|l|}{ Postoperative assessment } \\
\hline Freedom from dialysis, $n(\%)$ & $390 / 437(89)$ \\
\hline Freedom from long-term dialysis, $n(\%)$ & $416 / 435(96)$ \\
\hline Freedom from reoperation, $n(\%)$ & $404 / 445(91)$ \\
\hline Freedom from ischemic stroke, $n(\%)$ & $373 / 440(85)$ \\
\hline Freedom from hemorrhagic stroke, $n(\%)$ & $421 / 428(98)$ \\
\hline
\end{tabular}

Abbreviations: BMI, body mass index; IQR, interquartile range; LVEF, left ventricular ejection fraction; RR, relative risk; SD, standard deviation; syst, systolic.

${ }^{a}$ Missing data lead to varying total numbers.

\section{Statistical Methods}

Freedom from events was analyzed using Kaplan-Meier curves and reported as estimate at 1, 3, 5, and, if reasonable, 10 years \pm standard error. Groups were compared using the log-rank test. The effect of continuous and binary variables was analyzed using univariate Cox-regression. Odds ratios (OR) are reported with $95 \%$ confidence intervals (CI). A multivariable logistic model was applied to assess 
Table 3 Univariate analysis of overall mortality

\begin{tabular}{|l|l|l|l|}
\hline Risk factor & OR & $95 \% \mathrm{Cl}$ & $p$ Value \\
\hline Chronic obstructive lung disease & 1.533 & $0.924-2.541$ & 0.098 \\
\hline Creatinine $>200 \mu \mathrm{mol} / \mathrm{L}$ & 2.176 & $1.193-3.97$ & 0.011 \\
\hline Diameter ascending aorta $>45 \mathrm{~mm}$ & 0.901 & $0.59-1.377$ & 0.630 \\
\hline Arterial hypertension & 1.817 & $0.991-3.331$ & 0.054 \\
\hline Diabetes mellitus & 1.1 & $0.463-2.608$ & 0.83 \\
\hline Affected left coronary artery & 1.369 & $0.751-2.497$ & 0.305 \\
\hline Affected right coronary artery & 1.378 & $0.842-2.257$ & 0.202 \\
\hline Redo surgery & 1.628 & $0.847-3.129$ & 0.144 \\
\hline Cross-clamp time & 1.006 & $1.003-1.009$ & $<0.001$ \\
\hline Cerebral perfusion time & 1.015 & $1.006-1.024$ & 0.001 \\
\hline Impaired left ventricular function & 0.965 & $0.945-0.986$ & 0.001 \\
\hline EuroSCORE & 1.168 & $1.059-1.289$ & 0.002 \\
\hline BMI & 1.003 & $0.962-1.046$ & 0.88 \\
\hline Age & 1.037 & $1.021-1.054$ & $<0.001$ \\
\hline
\end{tabular}

Abbreviations: $\mathrm{BMI}$, body mass index; $\mathrm{Cl}$, confidence interval; OR, odds ratio.

independent preoperative risk factors for overall outcome. We considered age, renal impairment, and reduced left ventricular ejection fraction, the preoperative risk factors that were statistically significant in univariate analysis for inclusion. EuroSCORE levels as a score of different factors was not considered for multivariate analysis. With regard to fewer events of postoperative neurologic and renal impairment, no appropriate multivariate analysis was possible for these morbidity aspects. Analysis was performed using IBM SPSS Statistics (Version 22. Armonk, New York, United States).

\section{Results}

\section{Survival}

Overall, 1-, 5-, and 10-year survival rates were $82.8 \pm 1.8 \%$, $73.6 \pm 2.4 \%$, and $59.3 \pm 3.9$, respectively. Preoperative renal impairment $(p=0.011)$, higher age $(p<0.001)$, reduced left ventricular ejection fraction $(p=0.001)$, higher numeric EuroSCORE levels $(p=0.002)$, longer cross-clamp times $(p<0.001)$, and longer cerebral perfusion times $(p=0.001)$ were predictors of mortality at any time point during follow-up ( - Table 3 ). In the multivariate analysis ( - Table 4) preoperative renal impairment $(p=0.001)$, higher age $(p<0.001)$, and reduced left ventricular ejection fraction $(p<0.001)$ were independent preoperative risk factors for mortality. No significant distribution difference was observed between patients with or without critical preoperative status in terms of elevated creatinine levels greater than $200 \mu \mathrm{mol} / \mathrm{L}(p=0.077)$. Up to 4 years survival curves diverge between patients with and without preoperative elevated creatinine levels. After 4 years only few patients at risk are left in the preoperative elevated creatinine group (-Fig. 1).
The total number of deaths was 120 . Detailed in-hospital records from 62 patients were available. Of these, 41 deaths were aortic and 9 cardiac related. Three were due to infection and three to bleedings. Six patients had other causes of death. 58 patients died during follow-up in an ambulant setting. No detailed medical reports or autopsy results were available for these patients.

\section{Dialysis}

Overall risk for new dialysis was $6 \pm 1.8 \%, 10 \pm 1.7 \%$, and $13 \pm 2 \%$ within 1,3 , and 5 years after surgery for acute type $A$ aortic dissection. Preoperative renal impairment $(p<0.001)$, higher age $(p=0.022)$, higher numeric EuroSCORE levels $(p=0.022)$, and prolonged cross-clamp and cerebral perfusion times $(p<0.001 ; p<0.001)$ were predictive for the need of perioperative dialysis (-Table 5 ).

Predictors for long-term dialysis were preoperative renal impairment $(p<0.001)$ and prolonged cross-clamp and cerebral perfusion time $(p<0.001 ; p<0.001)$, ( - Table 6$)$. No statistical evaluation was possible for patients with chronic obstructive pulmonary disease (COPD), affected left or right coronary ostium, or redo surgery due to low event rate. Overall risk for long-term dialysis was $3 \pm 0.7 \%$ and $5 \pm 1.3 \%$ within 3 and 5 years, respectively, after surgery for acute type A aortic dissection.

\section{Neurologic Impairment}

Overall estimated 1-, 3-, and 5-year freedom from neurologic impairment was $90 \pm 1.5 \%, 87 \pm 1.7 \%$, and $84 \pm 2.1 \%$, respectively. Higher age $(p=0.045)$ and prolonged cross-clamp and cerebral perfusion time $(p=0.038 ; p=0.007)$ were predictors for disabling stroke ( - Table 7 ). Seven hemorrhagic strokes occurred during the complete postoperative period ( $10 \%$ of all events). 
104 Survival, Neurologic Injury, and Kidney Function after Aortic Dissection Schoenrath et al.

Table 4 Multivariate analysis of preoperative predictors for overall mortality

\begin{tabular}{|l|l|l|l|}
\hline Risk factor & OR & $95 \% \mathrm{Cl}$ & $p$ Value \\
\hline Creatinine $>200 \mu \mathrm{mol} / \mathrm{L}$ & 2.858 & $1.532-5.335$ & $=0.001$ \\
\hline Impaired left ventricular function & 0.443 & $0.296-0.664$ & $<0.001$ \\
\hline Age & 1.050 & $1.032-1.069$ & $<0.001$ \\
\hline
\end{tabular}

Abbreviations: $\mathrm{Cl}$, confidence interval; OR, odds ratio.

\section{Discussion}

In addition to classic risk factors, survival after type A aortic dissection is affected by preexisting renal impairment. Risk factors for any neurologic injury also during follow-up were age and prolonged cross-clamp and cerebral perfusion time. Preexisting renal impairment is predictive of any postoperative renal failure.

Overall 1-, 3-, 5-, and 10-year survival rates were estimated $83 \%, 78 \%, 74 \%$, and $59 \%$, respectively. The initial attrition rate is primarily due to the event of acute aortic dissection per se and related problems in untreated segments of the aorta as well as to cardiac disease, as indicated from 62 detailed inhospital medical records from death patients in our cohort. Most series addressing surgery for acute type A aortic dissection focus on perioperative outcome and often lack reporting of survival greater than 4 years. ${ }^{3,6-10}$ The few contemporary trials with longer follow-up show comparable outcomes. ${ }^{11}$ However, patient number reported is substantially smaller in most studies.
Renal impairment, higher age, and reduced left ventricular ejection fraction were independent preoperative predictors of mortality. Impaired renal function has been confirmed in patients with stroke, ${ }^{12}$ coronary artery disease, ${ }^{13}$ diabetes, ${ }^{14}$ hypertension ${ }^{15}$ and in the general population ${ }^{16}$ as an independent predictor of mortality. However, no other trial had focused on preoperative renal impairment in patients with acute type A aortic dissection to date. We identified preoperative renal impairment as an independent predictor for mortality in surgically treated patients with acute type A aortic dissection. This finding was independent from critical preoperative state, so we presume not only the acute impairment in the setting of acute cardiogenic shock or as an entity of malperfusion syndrome with potential reversal after correcting the underlying pathological mechanisms but also the long-term manifestation of renal disease affects survival. We suggest that the pathophysiologic processes underlying vascular endothelial dysfunction due to renal disease may explain our findings. This is supported by the aspect that over the first years survival curves with subject to preoperative

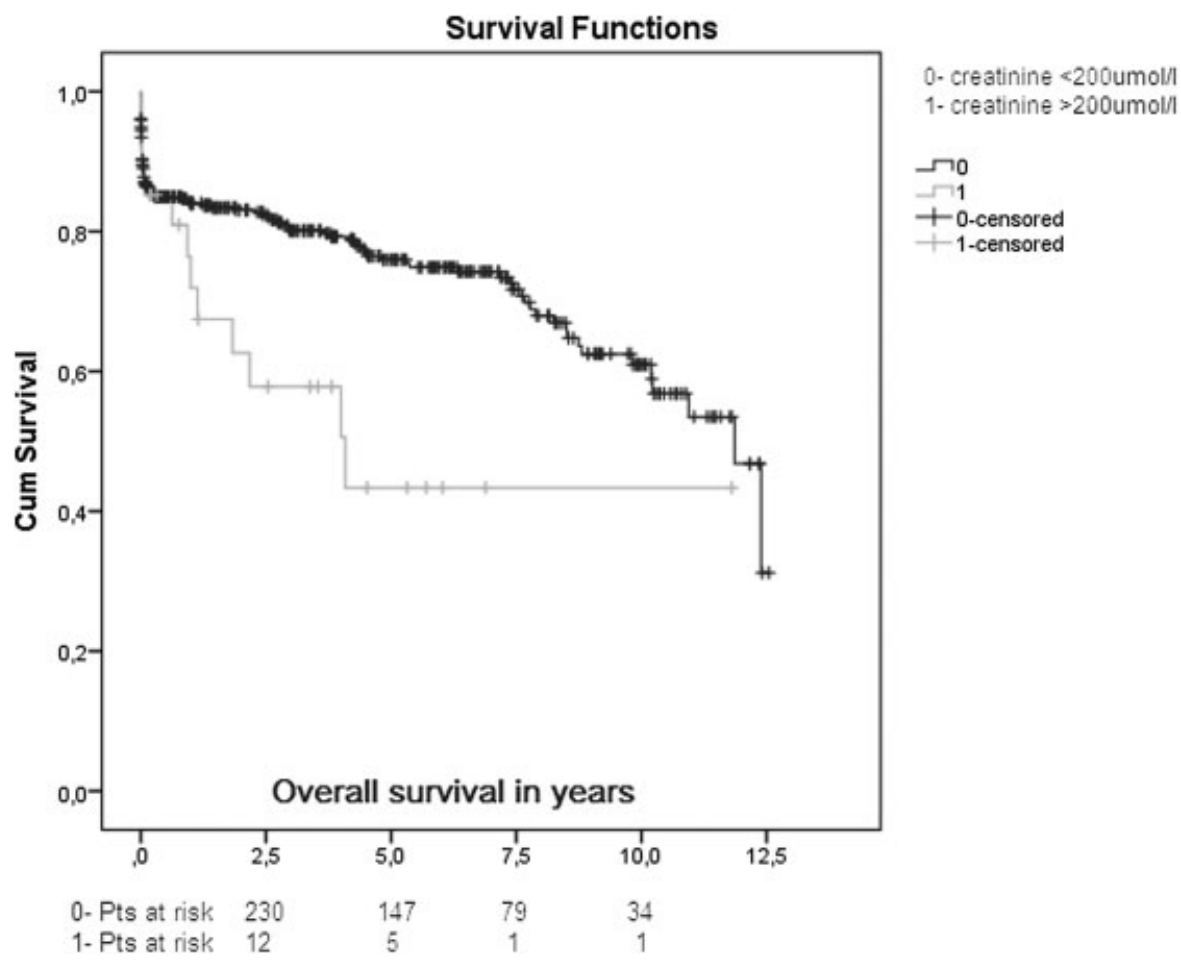

Fig. 1 Kaplan-Meier curve of overall survival subject to preoperative renal impairment. Pts, patients. 
Table 5 Univariate analysis of overall new dialysis

\begin{tabular}{|l|l|l|l|}
\hline Risk factor & OR & $95 \% \mathrm{Cl}$ & $p$ Value \\
\hline Chronic obstructive lung disease & 0.943 & $0.288-3.092$ & 0.923 \\
\hline Creatinine $>200 \mu \mathrm{mol} / \mathrm{L}$ & 5.278 & $2.277-12.235$ & $<0.001$ \\
\hline Diameter ascending aorta $>45 \mathrm{~mm}$ & 0.836 & $0.391-1.785$ & 0.644 \\
\hline Arterial hypertension & 0.756 & $0.339-1.687$ & 0.495 \\
\hline Diabetes mellitus & 0.704 & $0.199-2.485$ & 0.585 \\
\hline Affected left coronary artery & 0.356 & $0.049-2.605$ & 0.309 \\
\hline Affected right coronary artery & 0.415 & $0.099-1,732$ & 0.228 \\
\hline Redo surgery & 1.735 & $0.530-5.6778$ & 0.363 \\
\hline Cross-clamp time & 1.011 & $1.006-1.015$ & $<0.001$ \\
\hline Cerebral perfusion time & 1.029 & $1.018-1.040$ & $<0.001$ \\
\hline Impaired left ventricular function & 0.996 & $0.962-1.032$ & 0.84 \\
\hline EuroSCORE & 1.164 & $1.021-1.326$ & 0.022 \\
\hline BMI & 1.023 & $0.986-1.081$ & 0.42 \\
\hline Age & 1.028 & $1.004-1.054$ & 0.022 \\
\hline
\end{tabular}

Abbreviations: $\mathrm{BMI}$, body mass index; $\mathrm{Cl}$, confidence interval; OR, odds ratio.

renal impairment diverge. Therefore these findings are different to data reported by Tsai et al. who detected that acute kidney injury $24 \mathrm{~h}$ after surgery is an important predictor of mortality. ${ }^{17}$ One trial reported preoperative serum creatinine values ${ }^{18}$ but found no significant change in mortality with higher serum levels. Most important, different definitions of renal impairment may have led to these results. Our trial addressed patients with a KDIGO 2012 class G3b-4 (moderate to severe impaired renal function), whereas Pagni et al ${ }^{18}$ used a creatinine cutoff of larger than $1.4 \mathrm{mg} / \mathrm{dL}$, reflecting a mild to moderate impaired renal function (KDIGO class G2 to G3a). Lower total numbers (132 vs. 445 patients in our trial) and inclusion of nonsurgically managed patient might be additional confounding factors.
Our finding that impaired left ventricular function is an independent risk factor is supported by current literature. ${ }^{18}$

The discussion regarding age and outcome in acute type $\mathrm{A}$ aortic dissection has several aspects. As most studies do not report their exclusion criteria for subjecting or nonsubjecting elderly patients for surgery, outcomes might be somewhat biased as merely the biologically fittest will gain access to treatment. This might account for the fact that advanced age is a risk factor in several reports as it is not in others. Finally it has to be mentioned that the overall number of octogenarians in all series is low. Longer cross-clamp time and prolonged cerebral perfusion time reflecting the extent of disease are prescribed as risk factors previously and consistently in current literature. $^{18}$

Table 6 Univariate analysis of long-term dialysis ( $>1$ year after operation or until death)

\begin{tabular}{|l|l|l|l|}
\hline Risk factor & OR & $95 \% \mathrm{Cl}$ & $p$ Value \\
\hline Creatinine $>200 \mu \mathrm{mol} / \mathrm{L}$ & 15.636 & $3.775-64.765$ & $<0.001$ \\
\hline Diameter ascending aorta $>45 \mathrm{~mm}$ & 1.053 & $0.193-5.761$ & 0.952 \\
\hline Arterial hypertension & 1.534 & $0.189-12.524$ & 0.688 \\
\hline Diabetes mellitus & 2.272 & $0.276-18.731$ & 0.446 \\
\hline Cross-clamp time & 1.011 & $1.006-1.018$ & $<0.001$ \\
\hline Cerebral perfusion time & 1.031 & $1.014-1.048$ & $<0.001$ \\
\hline Impaired left ventricular function & 0.987 & $0.936-1.041$ & 0.63 \\
\hline EuroSCORE & 1.033 & $0.814-1.311$ & 0.79 \\
\hline BMI & 0.993 & $0.888-1.111$ & 0.90 \\
\hline Age & 1.006 & $0.971-1.043$ & 0.72 \\
\hline
\end{tabular}

Abbreviations: $\mathrm{BMI}$, body mass index; $\mathrm{Cl}$, confidence interval; $\mathrm{OR}$, odds ratio. 
Table 7 Univariate analysis of neurologic impairment

\begin{tabular}{|l|l|l|l|}
\hline Risk factor & OR & $95 \% \mathrm{Cl}$ & $p$ Value \\
\hline Chronic obstructive lung disease & 1.318 & $0.557-3.120$ & 0.530 \\
\hline Creatinine $>200 \mu \mathrm{mol} / \mathrm{L}$ & 0.923 & $0.222-3.826$ & 0.912 \\
\hline Diameter ascending aorta $>45 \mathrm{~mm}$ & 0.899 & $0.459-1.758$ & 0.755 \\
\hline Arterial hypertension & 1.018 & $0.485-2.138$ & 0.962 \\
\hline Diabetes mellitus & 0.639 & $0.184-2.219$ & 0.480 \\
\hline Affected left coronary artery & 0.236 & $0.032-1.720$ & 0.154 \\
\hline Redo surgery & 0.704 & $0.667-2.959$ & 0.632 \\
\hline Cross-clamp time & 1.005 & $1.000-1.010$ & 0.038 \\
\hline Cerebral perfusion time & 1.016 & $1.005-1.028$ & 0.007 \\
\hline Impaired left ventricular function & 1.007 & $0.975-1.040$ & 0.67 \\
\hline EuroSCORE & 0.980 & $0.863-1.113$ & 0.75 \\
\hline BMI & 0.937 & $0.877-1.001$ & 0.061 \\
\hline Age & 1.020 & $1.000-1.040$ & 0.045 \\
\hline
\end{tabular}

Abbreviations: $\mathrm{BMI}$, body mass index; $\mathrm{Cl}$, confidence interval; OR, odds ratio.

Overall risk for new dialysis was $6 \%$ in the first year after surgery and $13 \%$ in the 5 years after surgery for acute type $A$ aortic dissection. Risk factors for postoperative dialysis were preoperative renal impairment, higher age, higher numeric EuroSCORE levels, and prolonged cross-clamp and cerebral perfusion times. Tsai reported that $11.2 \%$ of his patients with surgically treated type A or B aortic dissection received temporary dialysis during the initial hospital stay after surgery. ${ }^{19}$ In a recent report, hypertension, lower limb malperfusion, and sepsis were independent risk factors for postoperative renal failure, ${ }^{17}$ but again only in the acute setting after aortic dissection. Several risk factors in the initial postoperative period (e.g., sepsis, malperfusion) lead to temporary need for dialysis, but with sufficient treatment, long-term need for renal replacement therapy should be avoidable. Of note no trial reporting on longterm dependency of dialysis after surgery for acute type A aortic dissection is available in current literature. To differentiate between temporary and prolonged need for dialysis, a second analysis was done only for patients with prolonged ( $>1$ year after surgery or until death) need for dialysis. After 5 years the risk of long-term dialysis was $5 \%$, and therefore substantially lower than the overall risk of new dialysis. Predictors for long-term dialysis were preoperative renal impairment and prolonged cross-clamp and cerebral perfusion time. Therefore, beside the extent of the disease, reflected by cross-clamp and cerebral perfusion time, preoperative renal impairment was responsible for a key factor of long term morbidity. Beside this, renal failure is an important risk factor for a broad range of other diseases, so treatment strategies in patients with postoperative renal impairment are crucial. Therefore blood pressure control and restoring renal blood flow in acute and subacute setting as well as treatment of an eventually underlying renal disease are of importance to decrease need for dialysis.
Overall estimated 1- and 5-year freedom from strokerelated neurologic impairment was $90 \%$ and $84 \%$, respectively. The IRAD study group reported a total of $6 \%$ of patients with acute type $A$ aortic dissection presenting with stroke initially. ${ }^{10}$ Aim of the surgery for acute type A aortic dissection with cerebral malperfusion is to restore cerebral perfusion that may resolve neurologic deficits. Pagni reported an incidence of $13.6 \%$ of postoperative stroke, with no definition for stroke given in the paper. ${ }^{18}$ Taken the emergency situation prior to operation into account with patients often arriving intubated in our tertiary care center and even lacking data about a complete preoperative neurological status, we focused on postoperative neurologic outcome. Therefore both preoperative neurologic complications and surgical risk factors have to be considered. Higher age and prolonged cross-clamp and cerebral perfusion time were predictors for disabling stroke in our analysis. The prospective analysis of neurologic dysfunction by Conzelmann and colleagues in GERAADA ${ }^{20}$ showed a similar pattern for duration of cardiopulmonary bypass and circulatory arrest. Other risk factors for postoperative stroke like malperfusion and dissection of the supra-aortic vessels ${ }^{20}$ were not analyzed in our study. Beside age, no other examined preoperative condition met significance in our study.

\section{Clinical Implications}

Trials for treatment of renal failure should include acute aortic dissection as a composite outcome intended to determine the overall impact of the treatment to investigate strategies (blood pressure control, improvement of lower limb perfusion) to positively influence pre- and postoperative renal impairment and lower mortality rate. Especially in high-risk patients aggressive prevention is substantial and therefore therapy addressing the most relevant risk factors is necessary. Further demographic changes will lead to increased event rates during the next years. 


\section{Study Limitations}

Like any retrospective review, this study has limitations. It is a cohort of unselected patients and the denominator of patients that declined or were not offered surgery is unknown. Our technique has evolved over the study period (i.e., cannulation site, root replacement type, surgical skill, cerebral perfusion) and results might also be affected by the different surgeons involved. With regard to neurologic impairment, no evaluation of spinal cord ischemia was performed and no evaluation targeting different surgical techniques or cerebral malperfusion imaging took place.

\section{Conclusion}

In addition to classic risk factors, survival after type A aortic dissection is affected by preexisting renal impairment. Risk factors for any neurologic injury also during follow-up were age and prolonged cross clamp- and cerebral perfusion time. Finally, preexisting renal impairment is predictive of any postoperative renal failure and therefore important for long term morbidity. Consequently, treatment and prevention strategies for renal failure during the acute and long-term course after acute type A aortic dissection are warranted and continuous monitoring of these patients remains mandatory.

\section{Conflict of Interest}

None.

\section{References}

1 Trimarchi S, Nienaber CA, Rampoldi V, et al; International Registry of Acute Aortic Dissection Investigators. Contemporary results of surgery in acute type A aortic dissection: The International Registry of Acute Aortic Dissection experience.J Thorac Cardiovasc Surg 2005;129(1):112-122

2 Krüger T, Conzelmann LO, Bonser RS, et al. Acute aortic dissection type A. Br J Surg 2012;99(10):1331-1344

3 Immer FF, Grobéty V, Lauten A, Carrel TP. Does malperfusion syndrome affect early and mid-term outcome in patients suffering from acute type A aortic dissection? Interact Cardiovasc Thorac Surg 2006;5(2):187-190

4 Czerny M, Krähenbühl E, Reineke D, et al. Mortality and neurologic injury after surgical repair with hypothermic circulatory arrest in acute and chronic proximal thoracic aortic pathology: effect of age on outcome. Circulation 2011;124(13):1407-1413

5 Roques F, Nashef SA, Michel P, et al. Risk factors and outcome in European cardiac surgery: analysis of the EuroSCORE multinational database of 19030 patients. Eur J Cardiothorac Surg 1999; 15(6):816-822, discussion 822-823
6 Skripochnik E, Friedman P, Michler RE, Neragi-Miandoab S. The outcome of surgical management of type A aortic dissection. Asian Cardiovasc Thorac Ann 2013;22(6):687-693

7 Haldenwang PL, Wahlers T, Himmels A, et al. Evaluation of risk factors for transient neurological dysfunction and adverse outcome after repair of acute type A aortic dissection in 122 consecutive patients. Eur J Cardiothorac Surg 2012;42(5):e115-e120

8 Di Eusanio M, Trimarchi S, Patel HJ, et al. Clinical presentation, management, and short-term outcome of patients with type A acute dissection complicated by mesenteric malperfusion: observations from the International Registry of Acute Aortic Dissection. J Thorac Cardiovasc Surg 2013;145(2):385-390.e1

9 Demondion P, Ramadan R, Azmoun A, et al. Aortic wrapping for Stanford type A acute aortic dissection: short and midterm outcome. Ann Thorac Surg 2014;97(5):1590-1596

10 Bossone E, Corteville DC, Harris KM, et al. Stroke and outcomes in patients with acute type A aortic dissection. Circulation 2013; 128(11, Suppl 1):S175-S179

11 Di Marco L, Pacini D, Leone A, et al. Long-term outcome after acute type A aortic dissection: does an age limit still exist? J Cardiovasc Surg (Torino) 2014;55(3):359-365

12 Ani C, Ovbiagele B. Relation of baseline presence and severity of renal disease to long-term mortality in persons with known stroke. J Neurol Sci 2010;288(1-2):123-128

13 Klausen K, Borch-Johnsen K, Feldt-Rasmussen B, et al. Very low levels of microalbuminuria are associated with increased risk of coronary heart disease and death independently of renal function, hypertension, and diabetes. Circulation 2004;110(1): 32-35

14 Rossing P, Hougaard P, Borch-Johnsen K, Parving H-H. Predictors of mortality in insulin dependent diabetes: 10 year observational follow up study. BMJ 1996;313(7060):779-784

15 Viazzi F, Leoncini G, Conti N, et al. Combined effect of albuminuria and estimated glomerular filtration rate on cardiovascular events and all-cause mortality in uncomplicated hypertensive patients. J Hypertens 2010;28(4):848-855

16 Weiner DE, Tighiouart H, Amin MG, et al. Chronic kidney disease as a risk factor for cardiovascular disease and all-cause mortality: a pooled analysis of community-based studies. J Am Soc Nephrol 2004;15(5):1307-1315

17 Tsai HS, Tsai FC, Chen YC, et al. Impact of acute kidney injury on one-year survival after surgery for aortic dissection. Ann Thorac Surg 2012;94(5):1407-1412

18 Pagni S, Ganzel BL, Trivedi JR, et al. Early and midterm outcomes following surgery for acute type A aortic dissection. J Card Surg 2013;28(5):543-549

19 Trimarchi S, Eagle KA, Nienaber CA, et al; International Registry of Acute Aortic Dissection Investigators. Role of age in acute type A aortic dissection outcome: report from the International Registry of Acute Aortic Dissection (IRAD). J Thorac Cardiovasc Surg 2010; 140(4):784-789

20 Conzelmann LO, Hoffmann I, Blettner M, et al; GERAADA Investigators. Analysis of risk factors for neurological dysfunction in patients with acute aortic dissection type A: data from the German Registry for Acute Aortic Dissection type A (GERAADA). Eur J Cardiothorac Surg 2012;42(3):557-565 